\title{
The Impact of Financial Crisis of 2007 to 14 on the Australian Financial Firms
}

\author{
Yu Ling Hsiao \\ School of Business, Macau University of Science and \\ Technology, Macau \\ ylhsiao@must.edu.mo
}

\author{
Chang Qi Liu \\ School of Business, Macau University of Science and \\ Technology, Macau \\ mydream612216@qq.com
}

\begin{abstract}
The purpose of this paper is to apply the new test of financial market contagion to test for equity markets in Australian domestic financial firms during the global financial crisis of 2007 to 14 . The new approach of contagion is developed by Fry-McKibbin, Hsiao and Martin (2017) and this test is named as a joint test. This new test can be identified the transmission channels of financial contagion through joint comoments of correlation, cross-market skewness (co-skewness), cross-market kurtosis (co-kurtosis) and cross-market volatility (co-volatility) of the distribution of the asset returns. The proposed test is applied to investigate the Australian financial companies' contagion in equity markets during the global financial crisis of 2007 to 14 . The results reveal that the joint test (JT test) statistic provides the evidence of contagion from the US banking sector to all of the Australian financial firms during the financial crisis of 2007 to 14 .
\end{abstract}

\section{Keywords-Contagion; Joint Test; Global Financial Crisis}

\section{INTRODUCTION}

Three financial crises came one after another during the period of 2007-14. The subprime mortgage crisis broke out in mid-2007, followed by the global financial crisis of 2008 to 09 called the "Great Recession", and the final one was the European debt crisis at the beginning of 2010 occurred in the Europe zone. The magnitude of financial shocks for these crises was dramatic and worldwide which influenced not only the domestic assets markets where it happened, but also another regions' with who were connected by financial transactions and trades. Transmissions of these severe financial shocks from one assets market to another are always far exceeding expectations compared with the market linkage and the dependence structure in the normal period [4]. Forms of the unexpected change include the change in the codependence structures across financial markets, unusual correlation and also another additional crisis transmitting channels such as higher order co-moments of the assets returns [5]. The difference in volatility has been researched in [1]

For testing such unforeseen change in the many types of market linkages between two financial markets due to the financial crisis, the definition of "co-movement" or more accurately "contagion" has been present to name this phenomenon. There are many versions describing the terms comovement and contagion in the earlier researches, and this paper use the definition based on [3]: a significance increase in

Hsiao acknowledges funding from Macau University of Science and Technology Faculty Research Grant FRG-16-033-04 cross-market linkages after a shock. There are many ways measuring severe financial turbulence such as financial crisis and describing the effect of crisis transmitted from the crisis source country to another such as co-movement called contagion on the stock market of a region, but only few discuss further about the contagion effect on a domestic industry and investigate their financial performance transmission channels for contagion. [3] Detected the change in unconditional correlation coefficient to test for contagion. [2] Focused on the non-linear relationship. A class of new testing method was developed by [5], [6], [7] and [8] which used higher order comoments to test the properties of the distributions of assets return.

This article attempts to investigate the contagion effect on Australian financial companies. The definition of contagion phenomenon: a significant change in cross-market joint comoment after a financial shock [8] has been applied. The paper measures whether there was such a financial contagion from the US to Australian financial firms during the financial crisis during the period of 2007-2014 which consists of the US subprime mortgage crisis, global financial crisis (also called the Great Recession) and the European debt crisis by using the method of joint test, which consists of linear and higher order co-moments such as: cross-market correlation [3], cross-market skewness (or co-skewness: the relationship between the asset return in market $i$ and the return volatility in market j) [5], cross-market kurtosis (or co-kurtosis: the relationship between the asset return in market $\mathrm{i}$ and return skewness in market $\mathrm{j}$ ) and cross-market volatility (or co-volatility: the relationship between the return volatility of markets $i$ and j) [7]. The higher order co-moments are derived by assuming the distribution of markets stock return as a bivariate normal distribution with the higher order moments and co-moments, and the normality is certified by calculating the Lagrange Multiplier statistic. The results reveal that the joint test of contagion provides the evidence of contagion from the US to the Australian financial firms transmitting through the correlation, co-skewness, cokurtosis and co-volatility during the global financial crisis of 2007 to 14

The remainder of this paper is organized as follows. Section 2 discusses a number of preliminary empirical results including data filtering and identification of equity market shocks. Section 3 specifies the contagion test based on changes in joint co-moments. Section 4 presents the main empirical results. 
Section 5 contains some concluding comment and suggestions for future research.

\section{THE DATA AND SAMPLE}

This paper is to identify financial linkages between two assets markets and to test for the significance of contagion transmission channels during the financial crisis of 2007 to 14. Data consists of the daily US banking stock market index and daily stock prices of the 71 observations of Australian financial firms. The data is collected from Bloomberg and they are listed under the category of "Asian developed region, financial". Due to data available during the period of 2005 to 14 , only 71 financial firms are selected and included 27 financial services firms, 33 real estate companies, 7 banks and insurance companies with the number of 4 .

When detecting financial market contagion, the source crisis market needs to be defined. The crisis source is assumed to be the US banking sector which is calculated as the US Bank sector index [7]. The Australian daily stock price index and the US banking sector index were collected during the period of January $1^{\text {st }}, 2005$ to December $31^{\text {st }}, 2014$ so as to measure the change of the relationship between two assets markets. Based on the paper of [3], the stock prices were transformed into daily equity return calculated as:

$$
R_{l, t}=100\left(\ln \left(P_{l . t}\right)-\ln \left(P_{l . t-1}\right)\right),(1)
$$

where $P_{l . t}$ is the daily price of $l^{t h}$ company at time $t$. The precrisis or non-crisis period is defined as the date before the US subprime mortgage crisis happening and subscript with $x$ (from January $4^{\text {th }}, 2005$ to July $25^{\text {th }}, 2007$, the number of observation is $T_{x}=667$ ) and during the crisis period is denoted as $y$ (from July $26^{\text {th }}, 2007$ to December $31^{\text {st }}, 2014, T_{y}=1940$, which covered the US subprime mortgage crisis, global financial crisis and the European debt crisis). The chosen dates are according to [6], which processed a regime switching model to figure out. The regime switching model is estimated by using Bayesian simulation on the equity returns data of a source market (i.e. the US for the subprime mortgage crisis) to estimate trigger events for severe financial turbulence.

\section{JOINT TEST OF CONTAGION}

The joint test of contagion developed by [7] and [8] is based on identifying significant changes in correlation, coskewness, co-kurtosis and co-volatility together between a crisis period and a non-crisis period in the meantime. The noncrisis period is denoted as $x$ and during-crisis period as $y$. The test statistic $(J T)$ to test for contagion from a source market $i$ to a recipient market $j$ is:

$$
\begin{aligned}
& J T(i \rightarrow j)=\left(\frac{\hat{v}_{y \mid x_{i}}-\widehat{\rho}_{x}}{\sqrt{\frac{1}{T_{x}}+\frac{1}{T_{y}}}}\right)^{2}+\left(\frac{\widehat{\Psi}_{y}\left(r_{i}^{1}, r_{j}^{2}\right)-\widehat{\Psi}_{x}\left(r_{i}^{1}, r_{j}^{2}\right)}{\sqrt{\frac{2}{T_{x}}+\frac{2}{T_{y}}}}\right)^{2}+ \\
& \left(\frac{\widehat{\Psi}_{y}\left(r_{i}^{2}, r_{j}^{1}\right)-\widehat{\Psi}_{x}\left(r_{i}^{2}, r_{j}^{1}\right)}{\sqrt{\frac{2}{T_{x}}+\frac{2}{T_{y}}}}\right)^{2}+\left(\frac{\widehat{\Psi}_{y}\left(r_{i}^{1}, r_{j}^{3}\right)-\widehat{\Psi}_{x}\left(r_{i}^{1}, r_{j}^{3}\right)}{\sqrt{\frac{6}{T_{x}}+\frac{6}{T_{y}}}}\right)^{2}+
\end{aligned}
$$

$$
\begin{gathered}
\left(\frac{\widehat{\Psi}_{y}\left(r_{i}^{3}, r_{j}^{1}\right)-\widehat{\Psi}_{x}\left(r_{i}^{3}, r_{j}^{1}\right)}{\sqrt{\frac{6}{T_{x}}+\frac{6}{T_{y}}}}\right)^{2}+\left(\frac{\widehat{\Psi}_{y}\left(r_{i}^{2}, r_{j}^{2}\right)-\widehat{\Psi}_{x}\left(r_{i}^{2}, r_{j}^{2}\right)}{\sqrt{\frac{4}{T_{x}}+\frac{4}{T_{y}}}}\right)^{2}- \\
\left(\frac{\hat{v}_{y \mid x_{i}}-\widehat{\rho}_{x}}{\sqrt{\frac{1}{T_{x}}+\frac{1}{T_{y}}}}\right)\left(\frac{\widehat{\Psi}_{y}\left(r_{i}^{1}, r_{j}^{3}\right)-\widehat{\Psi}_{x}\left(r_{i}^{1}, r_{j}^{3}\right)}{\sqrt{\frac{1}{T_{x}}+\frac{1}{T_{y}}}}\right)- \\
\left(\frac{\hat{v}_{y \mid x_{i}}-\widehat{\rho}_{x}}{\sqrt{\frac{1}{T_{x}}+\frac{1}{T_{y}}}}\right)\left(\frac{\widehat{\Psi}_{y}\left(r_{i}^{3}, r_{j}^{1}\right)-\widehat{\Psi}_{x}\left(r_{i}^{3}, r_{j}^{1}\right)}{\sqrt{\frac{1}{T_{x}}+\frac{1}{T_{y}}}}\right),(2)
\end{gathered}
$$

where

$$
\hat{v}_{y \mid x_{i}}=\frac{\hat{\rho}_{y}}{\sqrt{1+\left(\left(\hat{\sigma}_{y i}^{2}-\hat{\sigma}_{x i}^{2}\right) / \hat{\sigma}_{x i}^{2}\right)\left(1-\hat{\rho}_{y}^{2}\right)}}, \text { (3) }
$$

and

$$
\begin{aligned}
& \widehat{\Psi}_{y}\left(r_{i}^{m}, r_{j}^{n}\right)=\frac{1}{T_{y}} \sum_{t=1}^{T_{y}}\left(\frac{y_{i, t}-\widehat{\mu}_{y i}}{\widehat{\sigma}_{y i}}\right)^{m}\left(\frac{y_{j, t}-\widehat{\mu}_{y j}}{\widehat{\sigma}_{y j}}\right)^{n} \\
& \widehat{\Psi}_{x}\left(r_{i}^{m}, r_{j}^{n}\right)=\frac{1}{T_{x}} \sum_{t=1}^{T_{x}}\left(\frac{x_{i, t}-\widehat{\mu}_{x i}}{\widehat{\sigma}_{x i}}\right)^{m}\left(\frac{x_{j, t}-\widehat{\mu}_{x j}}{\widehat{\sigma}_{x j}}\right)^{n}
\end{aligned}
$$

The non-crisis period is denoted as $x$, and the crisis period is denoted as $y$. The sample sizes of the non-crisis and crisis periods are $T_{x}$ and $T_{y}$ respectively. The correlation between the two asset returns is denoted as $\hat{\rho}_{x}$ (non-crisis period) and $\hat{\rho}_{y}$ (crisis period). $\hat{\mu}_{x i}, \hat{\mu}_{x j}, \hat{\mu}_{y i}$ and $\hat{\mu}_{y j}$ are the sample means of the asset returns for markets $i$ and $j$ during the two periods, and $\hat{\sigma}_{x i}, \hat{\sigma}_{x j}, \hat{\sigma}_{y i}$ and $\hat{\sigma}_{y j}$ are the corresponding sample standard deviations.

The first term of equation (2) measures changes in the adjusted crisis period correlation $\left(\hat{v}_{y \mid x_{i}}\right)$ compared to a noncrisis period correlation $\left(\hat{\rho}_{x}\right)$, while the next two part capture changes in both forms of co-skewness $(m=1, n=2 ; m=$ $2, n=1)$. The fourth and fifth terms measure changes in both forms of co-kurtosis $(m=1, n=3 ; m=3, n=1)$, while the sixth term captures changes in co-volatility $(m=2, n=2)$ across the two regimes (from the US to the Australian). The last two terms allow for the interaction effects between the even order moments.

If there is no contagion phenomenon during the financial crisis, the linear and higher order co-moments between the non-crisis and during-crisis period should be the same. To test that there is financial market contagion based on change in correlation, co-skewness, co-kurtosis and co-volatility between the non-crisis and crisis period, the null and alternative hypotheses are

$$
\begin{aligned}
& H_{0}: v_{y \mid x_{i}}=\rho_{x}, \Psi_{y}\left(r_{i}^{m}, r_{j}^{n}\right)=\Psi_{x}\left(r_{i}^{m}, r_{j}^{n}\right) \\
& H_{1}: v_{y \mid x_{i}} \neq \rho_{x}, \Psi_{y}\left(r_{i}^{m}, r_{j}^{n}\right) \neq \Psi_{x}\left(r_{i}^{m}, r_{j}^{n}\right)
\end{aligned}
$$

for both forms of co-skewness $(m=1, n=2 ; m=2, n=1)$, both forms of co-kurtosis ( $m=1, n=3 ; m=3, n=1)$ and co-volatility $(m=2, n=2)$. Under the null hypothesis of no contagion, the test statistic is asymptotically distributed as 
$J T \stackrel{d}{\rightarrow} \chi_{6}^{2}$. If the test statistic $(J T)$ is greater than the critical value 12.59 , we can reject the null hypothesis at $5 \%$ significant level. The result suggests that there is financial market contagion from asset market $i$ to market $j$ at $5 \%$ significance level.

Before conducting the joint test of contagion in equation (2), the stock data is filtered in the same way as in [3] to control for market fundamentals (i.e., cross market relationships that always exist) and address the serial correlation problems in the data set. That is, a vector autoregressive model (VAR) model is given by

$$
\begin{gathered}
R_{t}=\emptyset(L) R_{t}+\eta_{t,}(6) \\
R_{t}=\left\{x_{t}^{i}, x_{t}^{j}, y_{t}^{i}, y_{t}^{j}\right\}^{\prime},
\end{gathered}
$$

where $x_{t}^{i}$ and $y_{t}^{i}$ are the daily returns of source market $i$ (the US Banking index) in the non-crisis and crisis period, respectively. $x_{t}^{j}$ and $y_{t}^{j}$ are the returns of recipient market $j$ (Australian financial firms) in the non-crisis and crisis period. $R_{t}$ is the transposition vector of returns of stock markets and Australian financial firms during the non-crisis $(x)$ and crisis (y) periods; $\varnothing(L)$ is a vector of lags and $\eta_{t}$ is the term of the residual vector. According to the criteria of the sequential modified log-likelihood ratio test statistic $(L R)$ and Akaike information $(A I), L$ is selected as 5 . Residuals $\left(\eta_{t}\right)$ for the VAR (5) model are regarded as the financial shocks used for the calculation of the correlation, co-skewness, co-kurtosis and co-volatility of JT test statistic in equation (2).

\section{EMPIRICAL RESULTS}

The joint contagion test described in Section 3 is applied to test for contagion in Australian financial firms during the global financial crisis of 2007 to 14. The source market is defined as the US banking sector and the recipient firms are 71 selected Australian financial firms. The joint test developed by [8] is applied and the results of contagion are illustrated in the Table 1. Based on Table 1, all of the Australian financial firms except for Mirvac Group and Peet Ltd companies are proved to be influenced by the global financial crisis of 2007-14 with the source market to be the US banking sector since the joint test statistics are greater than critical value at 5\% significance level. The results suggest that the Australian financial sector is affected by the global financial crisis of 2007-14.

TABLE1 THE RESULTS OF JT TEST STATISTICS AND P-VALUE

\begin{tabular}{|c|c|c|c|}
\hline \multicolumn{4}{|c|}{ Table I, Cont. } \\
\hline Carindale Property Trust & 25.36 & 0.00 & $*$ \\
\hline Centrepoint Alliance Ltd & 71.70 & 0.00 & $*$ \\
\hline Centuria Capital Ltd & 360.61 & 0.00 & $*$ \\
\hline Challenger Ltd/Australia & 52.99 & 0.00 & $*$ \\
\hline Chapmans Ltd & 48.75 & 0.00 & $*$ \\
\hline Charter Hall Retail REIT & 555.23 & 0.00 & $*$ \\
\hline Credit Corp Group Ltd & 17.99 & 0.01 & $*$ \\
\hline Desane Group Holdings Ltd & 156.74 & 0.00 & $*$ \\
\hline Devine Ltd & 60.22 & 0.00 & * \\
\hline Dexus Property Group & 169.71 & 0.00 & $*$ \\
\hline DigitalX Ltd & 59061.09 & 0.00 & $*$ \\
\hline Eureka Group Holdings Ltd & 21.66 & 0.00 & $*$ \\
\hline Euroz Ltd & 130.57 & 0.00 & $*$ \\
\hline Finbar Group Ltd & 171.75 & 0.00 & $*$ \\
\hline First Growth Funds Ltd & 22.97 & 0.00 & $*$ \\
\hline Folkestone Education Trust & 26.74 & 0.00 & $*$ \\
\hline Folkestone Ltd & 95.20 & 0.00 & $*$ \\
\hline FSA Group Ltd & 103.60 & 0.00 & $*$ \\
\hline GPT Group & 134.15 & 0.00 & $*$ \\
\hline Homeloans Ltd & 147.62 & 0.00 & $*$ \\
\hline Hudson Investment Group Ltd & 593.64 & 0.00 & $*$ \\
\hline Hunter Hall International Ltd & 319.76 & 0.00 & $*$ \\
\hline IMF Bentham Ltd & 213.10 & 0.00 & $*$ \\
\hline Ingenia Communities Group & 102.85 & 0.00 & $*$ \\
\hline Insurance Australia Group Ltd & 5.50 & 0.48 & \\
\hline Investa Office Fund & 210.82 & 0.00 & $*$ \\
\hline IOOF Holdings Ltd & 52.84 & 0.00 & $*$ \\
\hline LandMark White Ltd & 1136.86 & 0.00 & $*$ \\
\hline LendLease Group & 604.65 & 0.00 & $*$ \\
\hline Lifestyle Communities Ltd & 132.71 & 0.00 & $*$ \\
\hline London City Equities Ltd & 168.84 & 0.00 & $*$ \\
\hline Macquarie Group Ltd & 58.40 & 0.00 & $*$ \\
\hline Mariner Corp Ltd & 127.53 & 0.00 & $*$ \\
\hline McMillan Shakespeare Ltd & 226.27 & 0.00 & $*$ \\
\hline Mirvac Group & 8.67 & 0.19 & \\
\hline Mortgage Choice Ltd & 357.68 & 0.00 & $*$ \\
\hline Murchison Holdings Ltd & 365.63 & 0.00 & $*$ \\
\hline National Australia Bank Ltd & 571.09 & 0.00 & $*$ \\
\hline NSX Ltd & 12.73 & 0.05 & $*$ \\
\hline Pacific Current Group Ltd & 28.04 & 0.00 & $*$ \\
\hline Peet Ltd & 6.55 & 0.36 & \\
\hline Perpetual Ltd & 234.45 & 0.00 & $*$ \\
\hline QBE Insurance Group Ltd & 173.84 & 0.00 & $*$ \\
\hline Quest Investments Ltd/Australia & 3816.55 & 0.00 & $*$ \\
\hline Queste Communications Ltd & 1249.33 & 0.00 & $*$ \\
\hline REA Group Ltd & 71.29 & 0.00 & $*$ \\
\hline Resapp Health Ltd & 42.50 & 0.00 & $*$ \\
\hline Rubik Financial Ltd & 1239.51 & 0.00 & $*$ \\
\hline Servcorp Ltd & 104.08 & 0.00 & $*$ \\
\hline Stockland & 100.67 & 0.00 & $*$ \\
\hline Sunland Group Ltd & 73.64 & 0.00 & $*$ \\
\hline Tian An Australia Ltd & 94.92 & 0.00 & $*$ \\
\hline Unity Pacific Group & 68.32 & 0.00 & $*$ \\
\hline Villa World Ltd & 36.88 & 0.00 & $*$ \\
\hline Westfield Corp & 378.30 & 0.00 & $*$ \\
\hline Westpac Banking Corp & 37.20 & 0.00 & $*$ \\
\hline
\end{tabular}

\begin{tabular}{lrrr}
\hline Australian firms & \multicolumn{1}{c}{ JT } & p-value & \\
\hline Abacus Property Group & 179.99 & 0.00 & $*$ \\
ALE Property Group & 73.75 & 0.00 & $*$ \\
AMP Ltd & 65.92 & 0.00 & $*$ \\
Ask Funding Ltd & 284.42 & 0.00 & $*$ \\
Aspen Group & 96.20 & 0.00 & $*$ \\
ASX Ltd & 13.64 & 0.03 & $*$ \\
Australia and New Zealand Banking & 327.36 & 0.00 & $*$ \\
Group Ltd & & & \\
Australian Ethical Investment Ltd & 146.76 & 0.00 & $*$ \\
Auswide Bank Ltd & 170.35 & 0.00 & $*$ \\
Aveo Group & 521.14 & 0.00 & $*$ \\
Axiom Properties Ltd & 74.50 & 0.00 & $*$ \\
Bank of Queensland Ltd & 216.80 & 0.00 & $*$ \\
Bendigo and Adelaide Bank Ltd & 1503.44 & 0.00 & $*$ \\
BWP Trust & 271.48 & 0.00 & $*$ \\
\hline
\end{tabular}

Note: The critical value is 12.59 at the $5 \%$ significance level, and JT test statistic in equation (2) follows the chi-square distribution with six degrees of freedom six $\left(\chi_{6}^{2}\right)$. “*” denotes at $5 \%$ level of significance level. Ltd and Corp are the abbreviation of limited and corporation. Real Estate Investment Trust is abbreviated as REIT.

\section{CONCLUSIONS}

This paper studies the impact of global financial crisis of 2007 to 14 on Australian financial firms. The joint test of contagion developed by [8] is applied to test for contagion between the US banking sector and the 71 Australian financial firms during the global financial crisis 2007 to 14 . The joint test has an advantage over the single channel tests of contagion in the literature that it can perform better when 
detecting the existence contagion by investigating the significant change of both linear and higher order co-moment channels together. When the contagion did happen, the joint test could detect it if there was a change in at least one channel of the correlation (the second order co-moment) to covolatility (the fourth order co-moment). The empirical results show that Australian financial sector is affected by the global financial crisis of 2007-14 transmitting from the US banking sector.

\section{REFERENCES}

[1] D. Baur, "Testing for Contagion - Mean and Volatility Contagion", Journal of Multinational Financial Management, 2003, 13, 405-22.

[2] C.A. Favero and F. Giavazzi, "Is the International Propagation of Financial Shocks Non-linear? Evidence from the ERM", Journal of International Economics, 2002, 57, 231-46.
[3] K. Forbes and R. Rigobon, "No Contagion, Only Interdependence: Measuring Stock Market Co-movements," vol. 57, The Journal of Finance, 2002, pp.2223-61.

[4] M. Dungey, R.A. Fry, B. Gonzalez-Hermosillo and V.L. Martin, "Transmission of Financial Crises and Contagion: A Latent Factor Approach", Oxford University Press, 2010.

[5] R.A. Fry, V.L. Martin and C. Tang, "A New Class of Tests of Contagion with Applications," vol. 28, Journal of Business Economics and Statistics, 2010, pp.423-37.

[6] R.A. Fry-McKibbin, C.Y. Hsiao and C. Tang, "Contagion and Global Financial Crises: Lessons from Nine Crises Episodes”, Open Economies Review, 2013, 1-50.

[7] R.A. Fry-McKibbin and C.Y. Hsiao, "Extremal Dependence Tests for Contagion," Econometrics Reviews, 2015, 1-24.

[8] R.A. Fry-McKibbin, C.Y. Hsiao and V.L. Martin, "Joint Tests of Contagion with Applications to Financial Crises," CAMA Working paper \#23, 2017. 